\title{
GREM1, FRZB and DKK1 mRNA levels correlate with osteoarthritis and are regulated by osteoarthritis-associated factors
}

Jeroen CH Leijten ${ }^{1}$, Steffan D Bos ${ }^{2}$, Ellie BM Landman ${ }^{1}$, Nicole Georgi ${ }^{1}$, Holger Jahr ${ }^{3}$, Ingrid Meulenbelt ${ }^{2}$, Janine N Post ${ }^{1}$, Clemens A van Blitterswijk ${ }^{4}$ and Marcel Karperien ${ }^{1 *}$

\begin{abstract}
Introduction: Osteoarthritis is, at least in a subset of patients, associated with hypertrophic differentiation of articular chondrocytes. Recently, we identified the bone morphogenetic protein (BMP) and wingless-type MMTV integration site (WNT) signaling antagonists Gremlin 1 (GREM1), frizzled-related protein (FRZB) and dickkopf 1 homolog (Xenopus laevis) (DKK1) as articular cartilage's natural brakes of hypertrophic differentiation. In this study, we investigated whether factors implicated in osteoarthritis or regulation of chondrocyte hypertrophy influence GREM1, FRZB and DKK1 expression levels.

Methods: GREM1, FRZB and DKK1 mRNA levels were studied in articular cartilage from healthy preadolescents and healthy adults as well as in preserved and degrading osteoarthritic cartilage from the same osteoarthritic joint by quantitative PCR. Subsequently, we exposed human articular chondrocytes to WNT, BMP, IL-1ß, Indian hedgehog, parathyroid hormone-related peptide, mechanical loading, different medium tonicities or distinct oxygen levels and investigated GREM1, FRZB and DKK1 expression levels using a time-course analysis.

Results: GREM1, FRZB and DKK1 mRNA expression were strongly decreased in osteoarthritis. Moreover, this downregulation is stronger in degrading cartilage compared with macroscopically preserved cartilage from the same osteoarthritic joint. WNT, BMP, IL-1 $\beta$ signaling and mechanical loading regulated GREM1, FRZB and DKK1 mRNA levels. Indian hedgehog, parathyroid hormone-related peptide and tonicity influenced the mRNA levels of at least one antagonist, while oxygen levels did not demonstrate any statistically significant effect. Interestingly, BMP and WNT signaling upregulated the expression of each other's antagonists.
\end{abstract}

Conclusions: Together, the current study demonstrates an inverse correlation between osteoarthritis and GREM1, FRZB and DKK1 gene expression in cartilage and provides insight into the underlying transcriptional regulation. Furthermore, we show that BMP and WNT signaling are linked in a negative feedback loop, which might prove essential in articular cartilage homeostasis by balancing BMP and WNT activity.

\section{Introduction}

A growing body of evidence suggests that hypertrophic differentiation of articular chondrocytes underlies the pathogenesis of osteoarthritis, at least in a subset of patients [1]. However, healthy articular cartilage is largely resistant to hypertrophic differentiation. In recent years many factors that are able to influence, or correlate with, the development of osteoarthritis have

\footnotetext{
* Correspondence: H.B.J.Karperien@utwente.nl

${ }^{1}$ Department of Developmental BioEngineering, MIRA Institute for Biomedical Technology and Technical Medicine, University of Twente, P.O. Box 217, 7500AE Enschede, the Netherlands

Full list of author information is available at the end of the article
}

been revealed. These include, but are not limited to, bone morphogenetic proteins (BMPs) [2,3], canonical wingless-type MMTV integration site family members (WNTs) [4,5], Hedgehog [6], interleukins [7,8], parathyroid hormone-related peptide (PTHrP) [9] and the transcription factors HIF2A [10] and RunX2 [11]. Of these factors, BMPs [12], WNT [13], Indian hedgehog (IHH) [14], HIF2A [15] and RunX2 [16] have also been identified as prohypertrophic factors.

Regardless of the instigating factor, hypertrophic differentiation of chondrocytes induces a catabolic shift.

\section{() Biomed Central}


Amongst others, IL-1 $\beta$ [17] and biomechanical stimulation, such as repetitive impulse loading [18], can also induce a catabolic shift. Additionally, tonicity might play a role in osteoarthritis, because it is significantly lower in osteoarthritic joints and is able to drive the expression of anabolic cartilage genes [19].

Healthy articular cartilage has an intrinsic mechanism that protects it from undergoing hypertrophic differentiation and subsequent catabolism [20]. Evidence suggests that articular cartilage is able to inhibit hypertrophic differentiation. For example, articular cartilage secretes soluble factors that inhibit hypertrophic differentiation of growth plate cartilage and chondrogenically differentiating mesenchymal stromal cells (MSCs) [21,22]. We recently identified the BMP and WNT antagonists Gremlin 1 (GREM1), frizzled-related protein (FRZB) and dickkopf 1 homolog (Xenopus laevis) (DKK1) as prime candidates for these articular cartilage secreted factors that inhibit chondrocyte hypertrophy [23]. Moreover, we have demonstrated that a SNP mutation in the GREM1 gene associates with hip osteoarthritis [23].

Based on these observations, we hypothesized that the expression of GREM1, FRZB and DKK1 is inversely correlated with osteoarthritis and their expression is influenced by established regulators of chondrocyte hypertrophy. In this study we have addressed this hypothesis by analyzing mRNA expression of GREM1, FRZB and DKK1 in human cartilage biopsies and in primary human chondrocytes stimulated with factors that are able to influence, or correlate with, the development of osteoarthritis.

\section{Methods}

\section{Patient material}

The use of human material was approved by the medical ethical committee of the Leiden University Medical Center. Written informed consent was received from or on behalf of all patients, including next-of-kin for child patients. Healthy preadolescent articular cartilage was obtained from four patients between 9 and 14 years old that underwent amputation surgery with cartilage-unrelated etiologies. Healthy adult articular was obtained from three post-mortem donors (70.3 \pm 11.2 years). Through the ongoing RAAK study [24] we sampled 23 donor joints ( $66.9 \pm 9.9$ years) with primary osteoarthritis during joint replacement surgery; cartilage specimens from areas visibly affected by the osteoarthritis process (osteoarthritis cartilage) and areas that appeared macroscopically intact (preserved cartilage) were taken for mRNA isolation and were analyzed pairwise.

\section{Cell isolation and cultivation}

Macroscopically intact articular cartilage from osteoarthritic femoral condyles was obtained from patients undergoing total knee replacement to establish primary chondrocyte cultures. Bovine cartilage of the femoral condyle was obtained from a local abattoir. Chondrocytes were isolated by collagenase treatment and cultured as previously described [25]. Chondrocytes were used in passage 2 unless otherwise stated. One should note that expression of GREM1, FRZB and DKK1 is not significantly altered between passage 0 and passage 2 chondrocytes (data not shown). Bone marrow-derived MSCs were isolated and cultured as described previously [26]. MG63 and Saos-2 were cultured in Dulbecco's modified Eagle's medium (Gibco, Grand Island, NY, USA) containing 10\% heat-inactivated fetal bovine serum (Biowhittaker, Walkersville, MD, USA), $100 \mathrm{U} / \mathrm{ml}$ penicillin (Gibco) with $100 \mathrm{mg} / \mathrm{ml}$ streptomycin (Gibco).

\section{Oxygen levels}

Freshly isolated human chondrocytes were seeded at 2,500 cells $/ \mathrm{cm}^{2}$ and cultured under conventional normoxic culture conditions ( $21 \%$ oxygen) or under hypoxic culture conditions ( $2.5 \%$ oxygen) using a hypoxia incubator (proox model C21; Biospherix, Redfield, NY, USA). Cells were cultured until 95\% confluency was reached.

\section{Tonicity}

Chondrocytes were seeded at 7,500 cells $/ \mathrm{cm}^{2}$, expanded in culture medium that was adjusted to either 280 or $380 \mathrm{mOsm}$, which approximates the osmolarity found in the synovial fluid of an osteoarthritic and healthy joint respectively [27]. We therefore refer to $280 \mathrm{mOsm}$ as being hypotonic. The osmolarity of the culture medium was adjusted with sodium chloride and reseeded at 20,000 cells $/ \mathrm{cm}^{2}$ as previously described [19]. After 24 hours, 0 or $500 \mathrm{ng} / \mathrm{ml}$ calcineurin inhibitor FK506 was supplemented to the culture medium. FK506 inhibits calcineurindependent NFAT signaling, which has been described to mediate tonicity-induced cell signaling in chondrocytes [19]. After an additional 6 days the chondrocytes were lysed for gene expression analysis.

\section{Mechanical stimulation}

A medium suspension of passage 2 human chondrocytes was mixed in a 1:1 ratio with liquefied ultrapure agarose (Invitrogen, Carlsbad, CA, USA) and loaded into a stainless steel bioreactor to create four $70 \mu \mathrm{l}$ constructs of two percent agarose containing $10 \times 10^{6} \mathrm{cells} / \mathrm{ml}$. The insert, loaded with four constructs, was installed in a custom-build bioreactor [28]. Using a custom-designed compression plate, two out of four constructs were mechanically loaded with $0.5 \mathrm{MPa}$, while the other two constructs remained unloaded. Compression was applied in a cyclical fashion with a frequency of $0.33 \mathrm{~Hz}$ with a loading phase of 50\%. During 48 hours, the loaded samples were either cyclically compressed without interruption (constant loading) or were unloaded for 1 hour after being cyclically compressed for 1 hour (intermittent loading). 


\section{Recombinant protein and compound stimulation}

All cell types were seeded at 5,000 cells $/ \mathrm{cm}^{2}$, grown to $95 \%$ confluency and subsequently exposed to a single dose of recombinant proteins. In all stimulation experiments, primary human chondrocytes of intact osteoarthritic cartilage, bovine chondrocytes of healthy articular cartilage, human bone marrow-derived MSCs or the cell lines MG63 and Saos- 2 were used at passage 2 . Cells received no medium refreshment after stimulation had occurred and were cultured up to 96 hours unless otherwise stated.

Human chondrocytes were exposed to 4, 20, 100 or $200 \mathrm{ng} / \mathrm{ml}$ recombinant human BMP2 (catalogue number 355-BM-010; R\&D Systems, Minneapolis, MN, USA), $100 \mathrm{ng} / \mathrm{ml}$ recombinant human WNT3A (catalogue number 5036-WN-010; R\&D Systems), $100 \mathrm{ng} / \mathrm{ml} \mathrm{re-}$ combinant human DKK1 (catalogue number 5439-DK -010; R\&D Systems), 3, 10 or $30 \mathrm{nM}$ GSK3 $\beta$ inhibitor GIN [29], 0.3, 1 or $3 \mu \mathrm{M}$ canonical WNT inhibitor PKF115-584 [30], 10 or $100 \mathrm{ng} / \mathrm{ml}$ recombinant human (catalogue number IL1B 201-LB-005; R\&D Systems), $10 \mu \mathrm{M}$ hedgehog signaling blocker cyclopamine (catalogue number BMLGR334-0001; Enzo Life Sciences, Farmingdale, NY, USA), $2.5 \mu \mathrm{g} / \mathrm{ml}$ recombinant IHH (catalogue number 1705- $\mathrm{HH}-$ 025; R\&D Systems) or $5 \times 10^{-7} \mathrm{M}$ recombinant human PTHrP (catalogue number SRP4651-50; Sigma Aldrich, St Louis, MO, USA). Second-passage human and bovine chondrocytes, second-passage human MSCs, MG63 and Saos-2 were stimulated with $10 \mathrm{nM}$ GIN and $100 \mathrm{ng} / \mathrm{ml}$ recombinant human WNT3A.

\section{Quantitative real-time RT-PCR}

At designated time points, cells were washed with PBS and lysed using trizol reagent (Invitrogen). Total RNA isolation, cDNA synthesis and gene expression analysis were performed as described previously [26]. Gene expression is reported as the relative fold-change between treated samples and untreated controls and is normalized to 0 hours post treatment unless stated otherwise. Primer sequences are available on our website [31].

\section{Viability}

Passage 2 human chondrocytes were seeded at 3,000 cells $/ \mathrm{cm}^{2}$. Upon reaching $95 \%$ confluency the chondrocytes were treated with 3, 10, $30 \mathrm{nM}$ GIN, 0.3, 1, $3 \mu \mathrm{M}$ PKF115$584,100 \mathrm{ng} / \mathrm{ml} D K K 1$ or $100 \mathrm{ng} / \mathrm{ml}$ WNT3A. After 48 hours the total metabolic activity of the cells was measured using Alamar blue (Invitrogen) according to the manufacturer's protocol.

\section{Statistical analysis}

Statistical differences between experimental treatments were analyzed using Student's t test or one-way analysis of variance. Each group consisted of three different donors, each measured at least in triplicate. Correlation between the expression of different genes was calculated using Pearson correlation. Statistical significance was set to $P<0.05$.

\section{Results}

GREM1, FRZB and DKK1 mRNA levels are decreased in osteoarthritic cartilage

Osteoarthritic cartilage is characterized by evidence of increased hypertrophic differentiation in at least a subset of patients [32]. Recently we reported that FRZB, GREM1 and $D K K 1$ function as natural brakes of the hypertrophic differentiation of articular cartilage [23]. Based on their proposed role, we hypothesized that the expression of these genes was decreased in osteoarthritic cartilage. GREM1, $F R Z B$ and DKK1 mRNA expression levels were therefore determined in paired specimens of macroscopically relatively preserved and degenerating osteoarthritic cartilage collected from a single osteoarthritic joint for 23 patients, healthy preadolescent cartilage and healthy adult articular cartilage. Healthy preadolescent and healthy adult articular cartilage both express these three genes at significantly higher levels than preserved and degrading osteoarthritic cartilage. Moreover, GREM1, FRZB and $D K K 1$ mRNA is significantly lower in degrading cartilage compared with macroscopically preserved cartilage (Figure 1) by 5.86 -fold, 4.34-fold and 2.83 fold respectively (in Additional file 1: Figure S1A). In addition, we demonstrated that this decrease is reproducible in almost all tested patients, with the exception of the patients with the lowest GREM1, FRZB and DKK1 mRNA expression levels. Finally, we demonstrated that the expression of all three genes was positively correlated with each other (in Additional file 1: Figure S1B).

\section{BMP2 enhances transcription of WNT antagonist FRZB and $D K K 1$}

Human chondrocytes were stimulated with a single pulse of BMP2 for up to 48 hours to investigate its effect on GREM1, $F R Z B$ and DKK1 mRNA levels. Functionality of the recombinant protein was demonstrated by a dose-dependent induction of the BMP target gene ID1. GREM1 mRNA levels remained unaltered compared with untreated chondrocytes after 48 hours. However, the expression of the WNT antagonists $F R Z B$ and $D K K 1$ were significantly upregulated in a dose-dependent manner (Figure 2). This suggests that BMPs were able to induce inhibition of canonical WNT signaling in a dose-dependent manner. Indeed, the WNT target gene AXIN2 was downregulated in a dose-dependent manner after BMP2 treatment.

\section{Canonical WNT signaling downregulates GREM1, FRZB and $D K K 1$ expression}

Chondrocytes were cultured in the presence or absence of either $100 \mathrm{ng} / \mathrm{ml}$ recombinant WNT3A, or a 


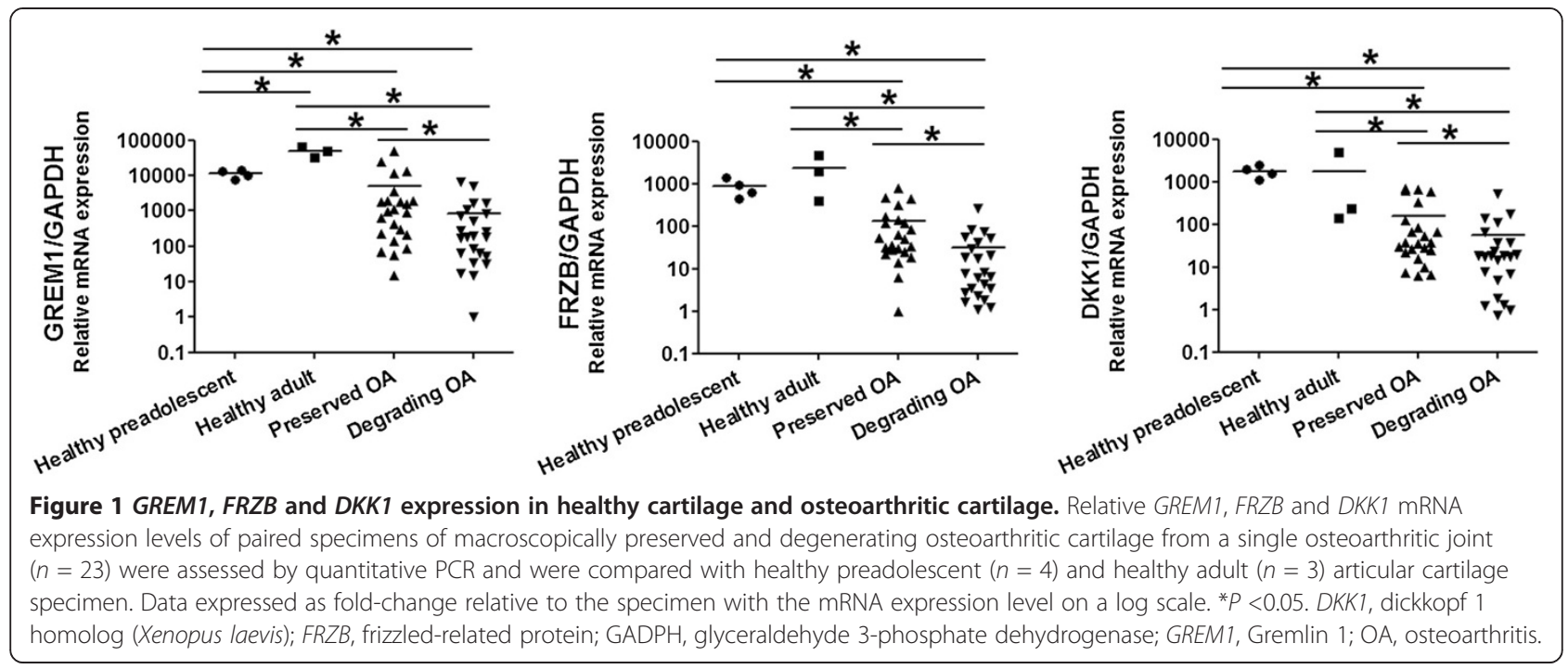

dose range of the GSK3 $\beta$ inhibitor GIN, which activates canonical WNT signaling. Both WNT3A and GIN dosedependently upregulated AXIN2 mRNA expression 48 hours after stimulation (Figure 3A). None of the conditions showed any signs of cytotoxicity as determined by phenotypical appearance and metabolic activity of the cells (Additional file 2).

Chondrocytes were then cultured in the presence or absence of $100 \mathrm{ng} / \mathrm{ml}$ WNT3A or $10 \mathrm{nM}$ GIN up to 96 hours. Both GIN and WNT3A induced canonical WNT signaling evidenced by an increase in AXIN2 mRNA expression. The effect was first detected after 6 hours and peaked between 24 and 48 hours post stimulation

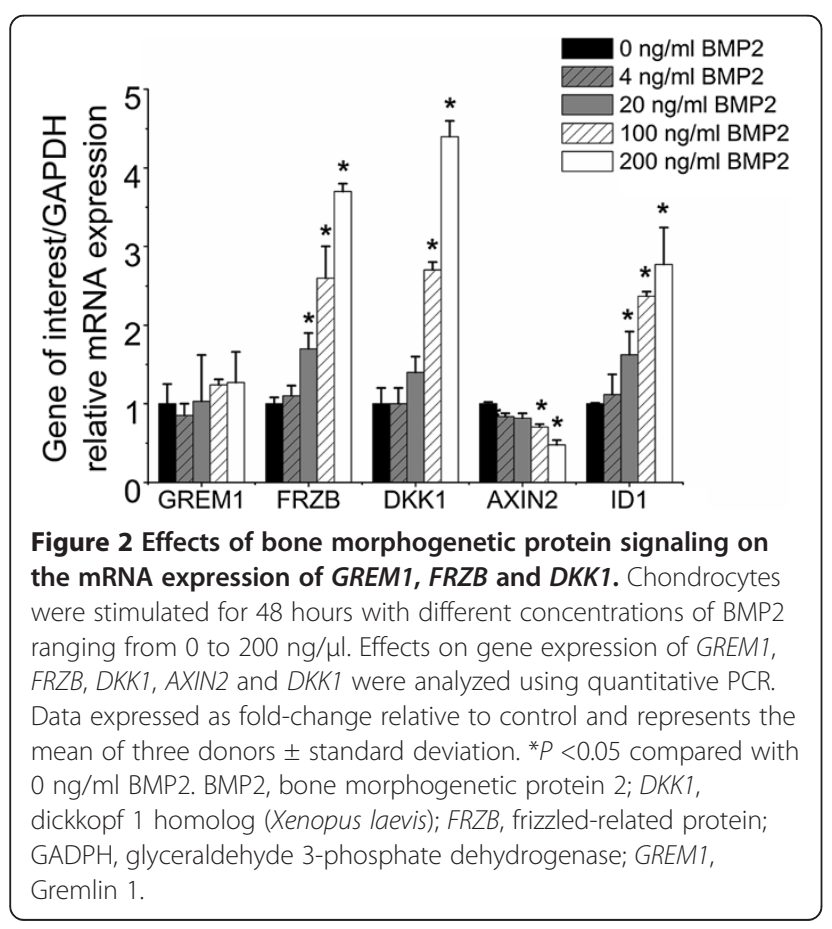

(Figure 3B). FRZB and DKK1 mRNA levels started to decrease 48 hours after stimulation and were significantly lower after 72 and 96 hours compared with untreated samples. This suggested that activation of WNT signaling resulted in the downregulation of WNT antagonists (Figure 3C, D). Activation of canonical WNT signaling transiently decreased GREM1 mRNA expression with lowest levels of mRNA expression 24 hours after treatment, after which the expression levels gradually returned to control levels (Figure 3E).

Additionally, we investigated the effects of enhanced WNT signaling on the mRNA levels of CHRD and CHRDL2, two BMP antagonists that have been suggested to play an inhibitory role in hypertrophic differentiation of chondrocytes [33,34]. Activation of canonical WNT signaling reduced CHRD and CHRDL2 mRNA levels with a maximal effect after 72 hours (in Additional file 3: Figure S3A, B). This suggested that activation of canonical WNT signaling might be able to influence BMP signaling by decreasing the expression of BMP antagonists. Indeed, mRNA levels of the established BMP target gene ID1 increased upon stimulation of canonical WNT signaling. This increase was preceded by a decrease in BMP antagonists' gene transcription (Figure 3F).

\section{Canonical WNT signaling regulates GREM1, FRZB and DKK1 mRNA levels in bovine chondrocytes, MG63, SAOS2, and human mesenchymal stromal cells}

As activation of canonical WNT signaling is correlated with a catabolic response in cartilage, at least in animal models, it is paramount for joint homeostasis that WNT signaling is tightly controlled. Typically, activation of critical pathways is accompanied by subsequent activation of negative feedback loops reducing pathway activity. Surprisingly, activation of canonical WNT signaling in primary human chondrocytes resulted in decreased FRZB and DKK1 

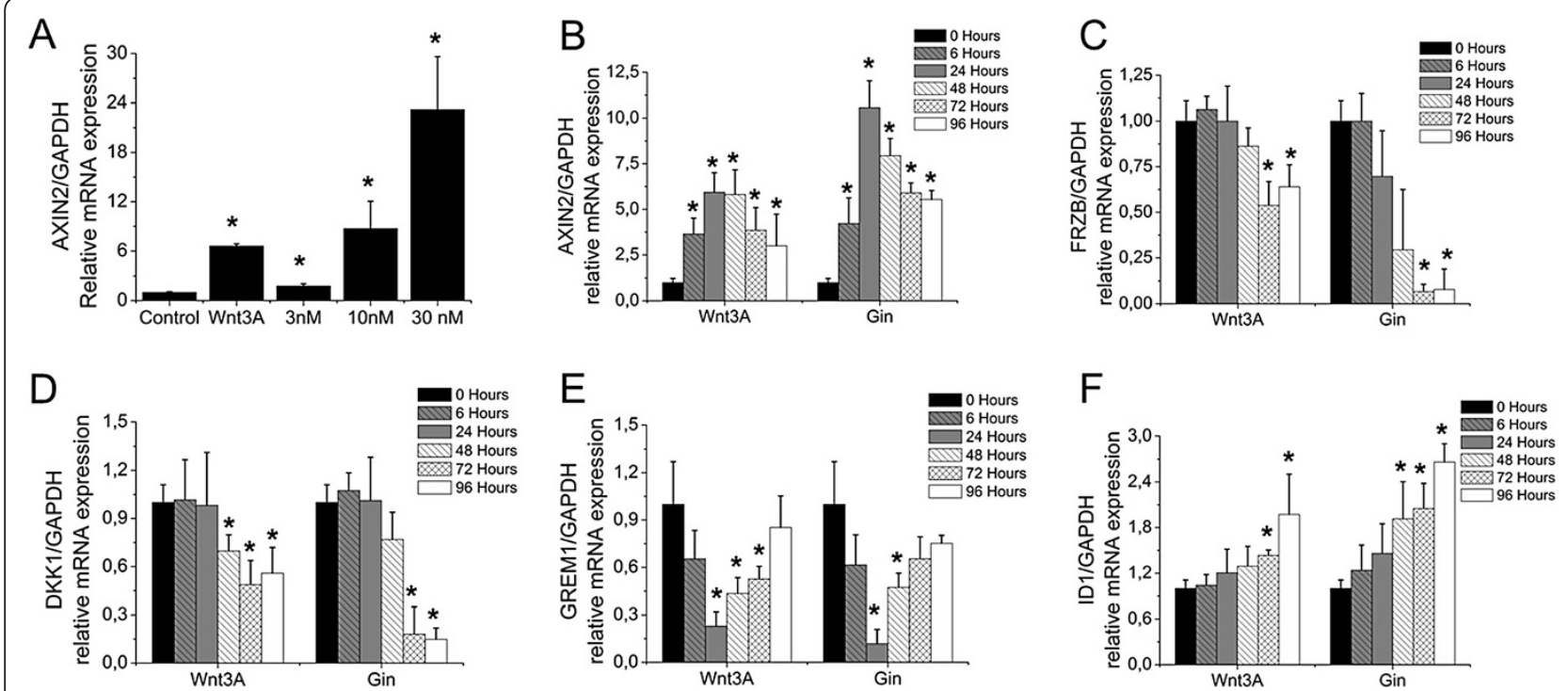

Figure 3 Effect of canonical WNT signaling on the mRNA expression of GREM1, FRZB and DKK1. (A) Primary human chondrocytes were exposed to $100 \mathrm{ng} / \mathrm{ml}$ WNT3A or three different concentrations of GIN. After 48 hours, AXIN2 mRNA expression was analyzed by quantitative PCR. (B) to (F) Chondrocytes were exposed to a single dose of $10 \mathrm{nM} \mathrm{GIN} \mathrm{or} 100 \mathrm{ng} / \mathrm{ml}$ WNT3A. At indicated time points, mRNA expression was analyzed by quantitative PCR of AXIN2 (B), FRZB (C), DKK1 (D), GREM1 (E) and ID1 (F). Data expressed as fold-change relative to untreated time-point-matched control and represents the mean of three donors \pm standard deviation. ${ }^{*} P<0.05$ compared with unstimulated cells $(\mathbf{A})$ or 0 hours of stimulation (B) to (F). DKK1, dickkopf 1 homolog (Xenopus laevis); FRZB, frizzled-related protein; GADPH, glyceraldehyde 3-phosphate dehydrogenase; GREM1, Gremlin 1; WNT, wingless-type MMTV integration site.

mRNA levels (Figure 3C, D). We therefore tested whether this downregulation was restricted to articular chondrocytes or was a general response across different cell types. Bovine chondrocytes, MG63s, SAOS-2 and MSCs were exposed to $100 \mathrm{ng} / \mathrm{ml}$ WNT3A or $10 \mathrm{nM} \mathrm{GIN}$ for 48 hours. Comparable with human chondrocytes, bovine chondrocytes downregulated FRZB and DKK1 mRNA levels after activation of canonical WNT signaling. In contrast, MG63 and SAOS-2 did not respond to GIN with changes in expression of FRZB and GREM1, respectively (Additional file 4). Like chondrocytes, human bone marrow-derived MSCs demonstrated a decrease in $F R Z B$ and $D K K 1$ mRNA levels upon stimulation of canonical WNT signaling. In contrast to human chondrocytes, GREM1 mRNA expression was upregulated by activating WNT signaling. Together this suggested that the response to canonical WNT signaling stimulation with regards to the mRNA expression levels of WNT and BMP antagonists is cell type dependent, but is conserved between species in articular chondrocytes.

\section{Inhibition of canonical WNT signaling induces mRNA expression of GREM1, FRZB and DKK1}

We next investigated the effect of inhibiting canonical WNT signaling on the mRNA expression levels of GREM1, $F R Z B$ and DKK1 using $100 \mathrm{ng} / \mathrm{ml}$ WNT antagonist DKK1 or $0.3,1$ or $3 \mu \mathrm{M}$ canonical WNT inhibitor PKF115-584. Treatment of human chondrocytes for 48 hours with either WNT inhibitor significantly reduced AXIN2 mRNA levels, except for $0.3 \mu \mathrm{M}$ PKF115-584 (in Additional file 5: Figure S5A). Treatment with 1 or $3 \mu \mathrm{M}$ PKF115-584 reduced the chondrocyte's metabolic activity and chondrocytes treated with $3 \mu \mathrm{M}$ PKF115-584 showed phenotypical signs of stress (Additional file 2). A concentration of $1 \mu \mathrm{M}$ PKF115-584 was therefore selected for further experimentation.

Treatment of chondrocytes up to 96 hours with a single dose of $100 \mathrm{ng} / \mathrm{ml} D K K 1$ or $1 \mu \mathrm{M}$ PKF115-584 resulted in a progressive decrease in AXIN2 mRNA levels, which became statistically significant between 72 and 96 hours post treatment (in Additional file 5: Figure S5B). In contrast, $F R Z B$ and $D K K 1 \mathrm{mRNA}$ levels steadily increased over time, which became significant between 24 and 48 hours post exposure (in Additional file 5: Figure S5C, D). Treatment with DKK1 or PKF115-584 increased GREM1 mRNA levels and this coincided with a subsequent decrease in ID1 mRNA levels (in Additional file 5: Figure S5E, F). Taken together, these data suggested that in human chondrocytes the GREM1, FRZB and DKK1 mRNA levels were inversely related to the activity of canonical WNT signaling.

\section{Effects of IL-1 $\beta$ stimulation on GREM1, FRZB and DKK1 mRNA expression}

Local injection of IL-1 $\beta$ into mouse knee joints resulted in the destabilization of joint homeostasis by inducing a catabolic shift in the articular cartilage [35]. We therefore investigated the effect of IL-1 $\beta$ on GREM1, FRZB and $D K K 1 \mathrm{mRNA}$ levels. Chondrocytes were stimulated with 
either a single dose of 10 or $100 \mathrm{ng} / \mathrm{ml}$ IL-1 $\beta$ or with a daily repeated dose of $10 \mathrm{ng} / \mathrm{ml} \mathrm{IL}-1 \beta$. Upon exposure to a single dose of IL-1 $\beta$, GREM1 mRNA levels decreased at 6 hours followed by a steady increase in mRNA expression, which became significantly higher than untreated samples after 72 hours. Interestingly, repeated treatment with of IL-1 $\beta$ decreased GREM1 mRNA expression after 6 hours, which returned to baseline after 24 hours (Figure 4A). FRZB mRNA levels were dose-dependently downregulated after exposure to IL-1 $\beta$. Daily treatment with $10 \mathrm{ng} / \mathrm{ml}$ was as effective as a pulse treatment with $100 \mathrm{ng} / \mathrm{ml}$. DKK1 mRNA levels decreased after stimulation with IL-1 $\beta$. This downregulation was transient with a single dose but persistent with a daily dose of IL-1 $\beta$ (Figure $4 \mathrm{~B}, \mathrm{C}$ ).

\section{Effects of physiological factors on GREM1, FRZB and DKK1 mRNA transcription}

Many physiological factors influence the homeostasis of articular cartilage. To determine whether such stimuli have an effect on the mRNA expression levels of GREM1, $F R Z B$ and $D K K 1$, chondrocytes were exposed to, for example, differing mechanical compression, oxygen tension and tonicity.

Chondrocytes encapsulated in three-dimensional hydrogels were cultured in the presence or absence of cyclic loading of the construct with $0.5 \mathrm{MPa}$ with a frequency of $0.33 \mathrm{~Hz}$, which was either continuously or intermittently applied over a culture period of 48 hours. Both continuous and intermittent loading significantly elevated GREM1 and $F R Z B$ mRNA levels compared with unloaded chondrocytes. $D K K 1$ mRNA levels were only significantly increased after intermittent loading of the construct (Figure 5A). Interestingly, intermittent loading was more effective in upregulating GREM1, FRZB and DKK1 mRNA expression than continuous loading.

Articular cartilage predominantly persists in a continuous state of hypoxia. Relief of this hypoxic stress is able to stimulate hypertrophic differentiation of hyaline cartilage [36]. Chondrocytes were therefore cultured under hypoxic $(2.5 \%)$ or normoxic $(21 \%)$ conditions. No detectable changes in GREM1, FRZB and DKK1 mRNA levels were observed between normoxic and hypoxic culture conditions (Figure 5B).

Osteoarthritis is associated with a decrease in tonicity of the synovial fluid and cartilage [27]. We therefore investigated the effect of tonicity on the mRNA levels of GREM1, FRZB and DKK1. Tonicity did not detectably affect GREM1 mRNA levels (Figure 5C). In contrast, tonicity tended to increase DKK1 mRNA levels and significantly increased $F R Z B$ mRNA levels. This effect was NFAT independent because FK506, which indirectly inhibits NFAT nuclear translocation, had no significant effect on GREM1, FRZB and DKK1 mRNA levels.

\section{Effects of PTHrP, IHH and cyclopamine on GREM1, FRZB and DKK1 mRNA expression}

PTHrP and IHH expression in articular cartilage is correlated with osteoarthritis [6,9]. In addition, PTHrP and IHH critically regulate the pace of hypertrophic differentiation in growth plate cartilage in a negative feedback loop. As GREM1, FRZB and DKK1 were able to inhibit hypertrophic differentiation in articular cartilage and mitigated longitudinal bone growth in explanted mouse fetal long bones [23], we investigated whether PTHrP and IHH were able to influence their mRNA expression. Chondrocytes were cultured up to 96 hours in the presence or absence of PTHrP, IHH and the hedgehog signaling blocker cyclopamine. GREM1 mRNA expression remained unchanged when stimulated with PTHrP, tended to transiently decrease after stimulation with $\mathrm{IHH}$ and was significantly increased by cyclopamine after 72 and 96 hours (in Additional file 6: Figure S6A). PTHrP nor IHH affected $F R Z B$ mRNA levels. Cyclopamine tended to decrease $F R Z B$ mRNA expression but this did not reach significance (in Additional file 6: Figure S6B). In

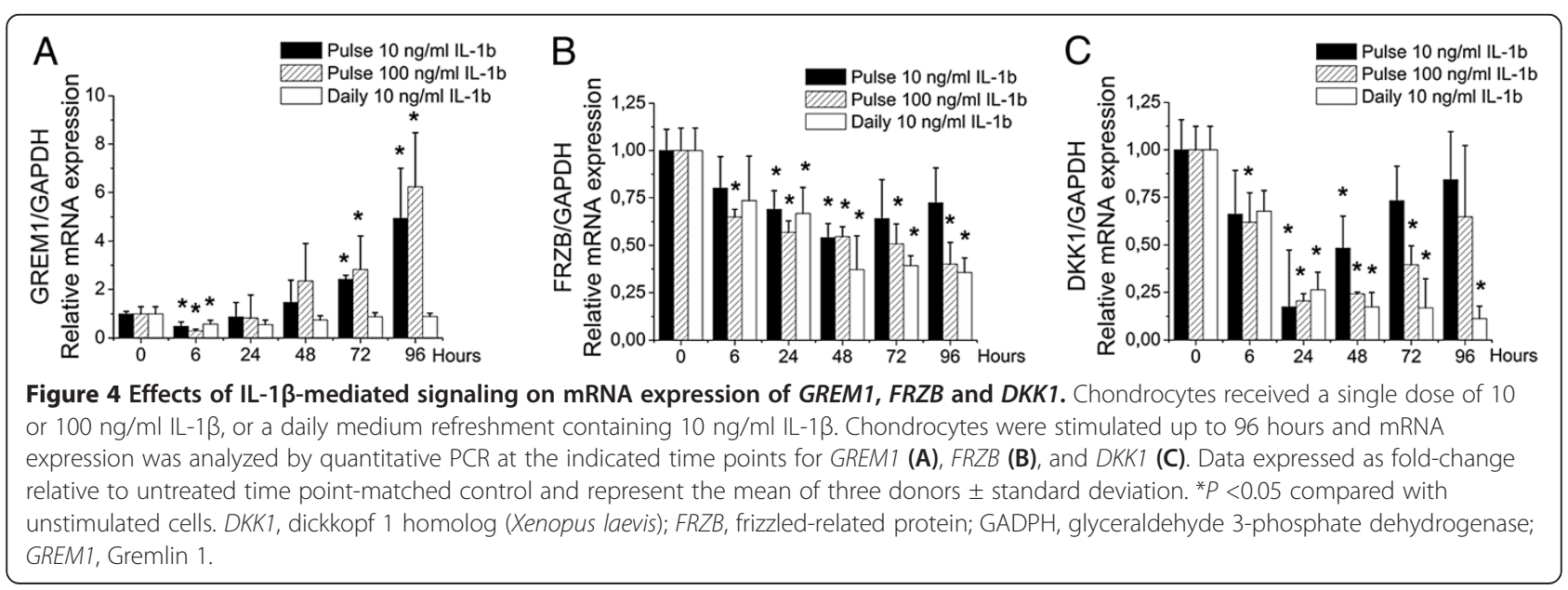




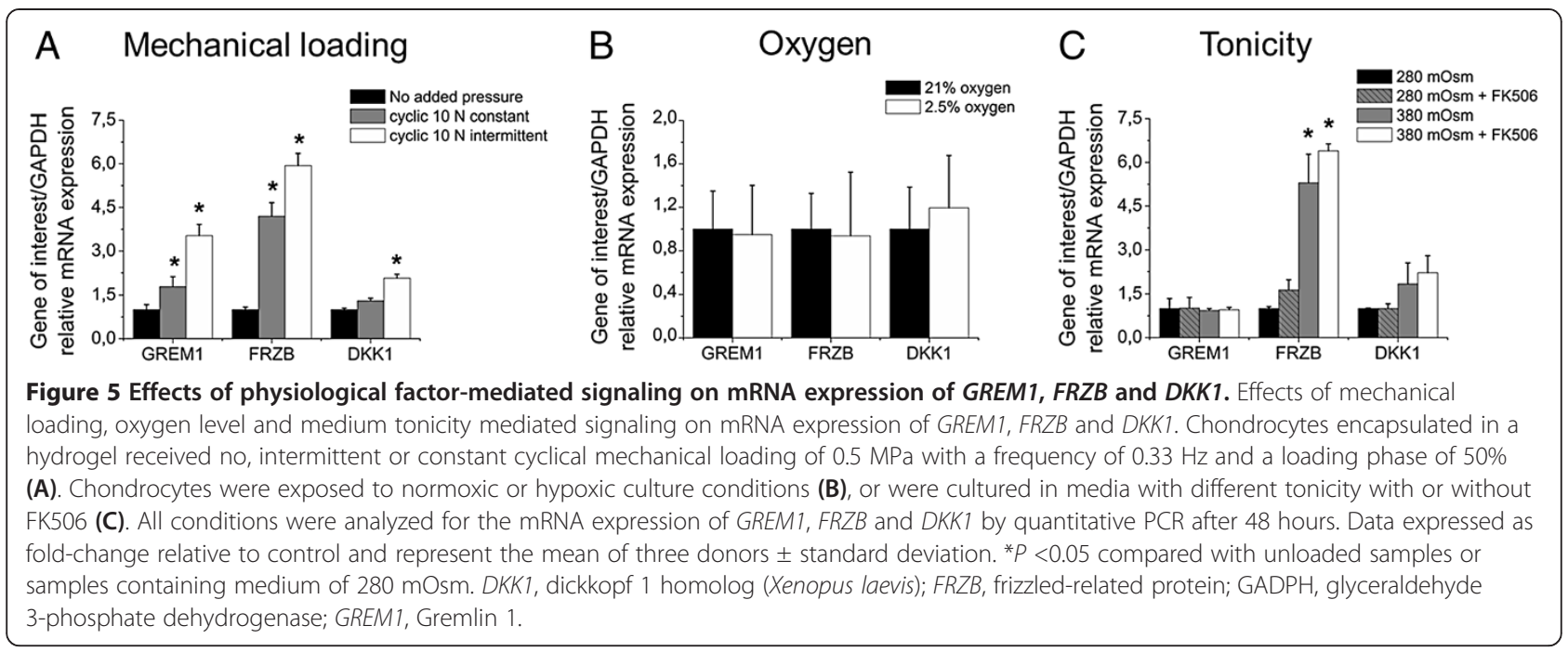

contrast, $D K K 1$ mRNA expression was significantly increased by cyclopamine and PTHrP treatment from 24 and 72 hours, respectively, but not by $\mathrm{IHH}$ (in Additional file 6: Figure S6C). The expression of established hedgehog and PTHrP target genes was used to verify the biological activity of each stimulus. GLI1 mRNA levels increased in the presence of $\mathrm{IHH}$ (in Additional file 6: Figure S6D) and decreased in the presence of cyclopamine (in Additional file 6: Figure S6E). CCND1 mRNA levels increased in the presence of PTHrP (in Additional file 6: Figure S6F). Taken together, this suggested that inhibition, but not activation, of IHH upregulated GREM1 and DKK1 mRNA levels.

\section{Discussion}

Recently we have reported that GREM1, FRZB and DKK1 are enriched in articular cartilage compared with other hyaline cartilage types and act as potent inhibitors of hypertrophic differentiation [23]. Moreover, we demonstrated an association between a genetic variation (SNP rs12593365) in a genomic control region of GREM1 and radiographic osteoarthritis of the hip. Based on these and other data we provided evidence that these BMP and WNT antagonists are important regulators of articular cartilage homeostasis by preventing hypertrophic differentiation of chondrocytes [23]. Since osteoarthritis is associated with deregulated hypertrophic differentiation in at least a subset of patients, we hypothesized that GREM1, FRZB and DKK1 mRNA expression levels are downregulated in osteoarthritis. In this study we report that the expression of GREM1, FRZB and $D K K 1$ mRNA was strongly decreased in osteoarthritic cartilage compared with healthy cartilage and was also decreased in degrading osteoarthritic cartilage compared with macroscopically preserved cartilage from the same osteoarthritic joint. In addition, we report on the effects of biochemical and biophysical stimuli associated with chondrocyte hypertrophy on GREM1, FRZB and DKK1
mRNA expression. Although the enzymatic isolation of the chondrocytes may have affected their gene expression levels, they were directly in line with our hypothesis. Furthermore, our claims are furthermore supported by recent observations demonstrating that osteophytic cartilage, which is prone to undergo endochondral ossification, has significantly less expression of GREM1 and FRZB compared with permanent articular cartilage [37].

GREM1, FRZB and DKK1 are secreted soluble antagonists. $F R Z B$ and $D K K 1$ are WNT antagonists and GREM1 is a BMP antagonist. GREM1 is also able to inhibit WNT signaling via unknown indirect mechanisms [38] and BMP signaling is able to repress WNT signaling [39]. Conversely, WNT signaling is also able to repress BMP signaling [40]. Activation of WNT signaling is well known to inhibit fibroblastic growth factor-dependent BMP repression [41]. Indeed, increased canonical WNT signaling resulted in increased BMP/SMAD signaling [42]. Although the crosstalk between BMP and WNT signaling is suggested to involve SMAD4 and MAPK p38, the exact mechanism has remained largely unknown [43].

Understanding the crosstalk between transforming growth factor beta/BMP and WNT signaling is desired because it plays important roles in the formation of several tissues, including bone, cartilage and intestinal epithelium [42,43]. While in previous studies the interplay is mainly characterized by activation of each other's ligands, in our study we provide evidence that antagonists may also play a central role in the crosstalk. We demonstrated in chondrocytes that this crosstalk is mediated, at least partially, via reciprocal transcriptional control of each other's antagonists. Consequently, our data suggest that the crosstalk between transforming growth factor beta/BMP and WNT signaling might act as a feedback loop that balances the activity of both pathways (Figure 6A). Specifically, activation of WNT signaling downregulates the expression of genes encoding 

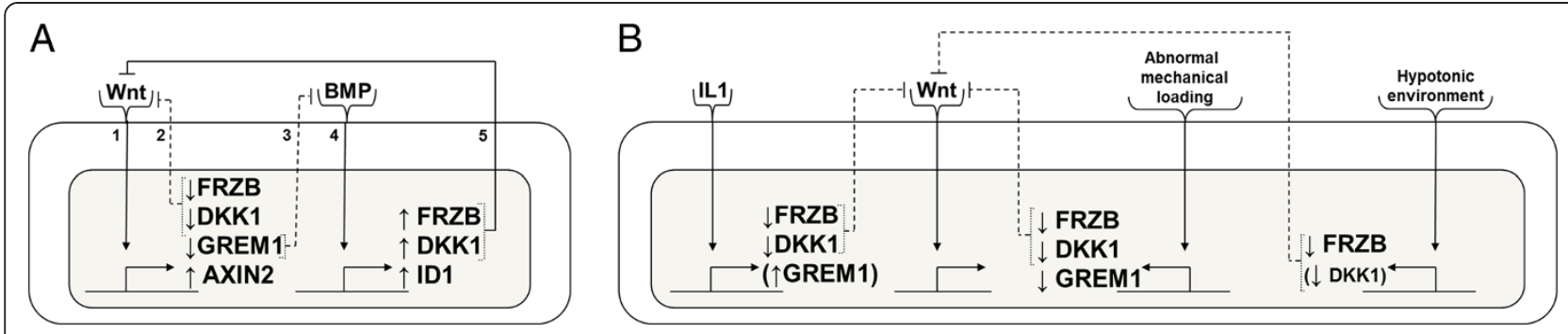

Figure 6 Preliminary working model of WNT and BMP signaling feedback loop and perturbation by osteoarthritis factors. (A) WNT and BMP signaling reciprocally regulates the transcription of other antagonists. Exposure of WNT agonists leads to activation of WNT signaling [1]. This activation results in the downregulation of WNT antagonists (for example, FRZB and DKK1), leading to less inhibition of WNT signaling [2]. Additionally, BMP antagonists (for example, GREM1) are downregulated, leading to less inhibition of BMP signaling [3]. Stronger BMP signaling results in the upregulation of WNT antagonists [4], establishing a negative feedback mitigating WNT signaling [5]. This feedback loop allows for tight control of both BMP and WNT signaling in articular cartilage contributing to homeostasis. (B) Established factors that influence cartilage homeostasis also perturb this feedback loop. IL-1ß, lack of mechanical stimulation and tonicity all decrease the mRNA levels of WNT and BMP antagonists, possibly resulting in a reset of the feedback loop, and contributing to the loss of cartilage homeostasis. BMP, bone morphogenetic protein; DKK1, dickkopf 1 homolog (Xenopus laevis); FRZB, frizzled-related protein; GADPH, glyceraldehyde 3-phosphate dehydrogenase; GREM1, Gremlin 1; WNT, wingless-type MMTV integration site.

BMP antagonists and is associated with the upregulation of BMP signaling. In turn, activation of BMP signaling results in increased expression of genes encoding WNT antagonists, which is associated with decreased WNT signaling.

Stringent control over the WNT pathway's activity is paramount for articular cartilage homeostasis because both exacerbated and repressed signaling results in an osteoarthritis-like phenotype, at least in animal models $[44,45]$. Perturbation of feedback loops that control the activity of WNT signaling would therefore allow for the disturbance of the natural homeostasis. Factors associated with disturbed joint homeostasis include, amongst others, IL-1 $\beta$, abnormal mechanical loading and hypotonicity. Although evidence suggests that short exposure to IL-1 $\beta$ results in minor joint inflammation without permanent joint destruction, continuous exposure to IL-1 $\beta$ results in joint degradation that bears striking resemblance with osteoarthritis $[7,34]$. Interestingly, IL-1 $\beta$ activates WNT signaling via a currently unknown mechanism [46]. Excessive mechanical loading of the joint induces the expression of IL-1 $\beta$ and catabolic proteins [47]. Interestingly, reduced joint loading by, for example, immobilization also results in increased catabolism via the upregulation of matrix metalloproteinases and aggrecanases [48]. In contrast, loading within the physiological range inhibits the expression of catabolic genes and shows a chondroprotective effect in the presence of IL$1 \beta$ [49]. Additionally, mechanical loading is able to regulate the activity of WNT signaling via a currently unknown mechanism [50]. Tonicity is able to regulate the expression of interleukins including IL-1 $\beta$ [51]. However, its effect on WNT signaling has remained largely uninvestigated. In this study, we present data implying that IL- $1 \beta$, lack of mechanical loading and hypotonicity downregulate the expression of the genes encoding hypertrophic differentiation inhibiting proteins including GREM1, FRZB and DKK1 (Figure 6B).
Our data suggest that these factors might be able to perturb the balance between BMP and WNT signaling by influencing the expression of both WNT and BMP antagonists in a manner that cannot be sequestered via their regular feedback loops. Consequently, it is tempting to speculate that these factors may contribute to an osteoarthritic-like phenotype, at least partially, via their ability to disturb the balance between WNT and BMP signaling. Although additional research is needed to sustain such a claim, recent evidence demonstrated that the addition of WNT and BMP antagonist sclerostin was able to prevent an IL-1 $\beta$-induced osteoarthritis-like phenotype [52].

Stimulation with BMPs, WNTs, IL-1, IHH, PTHrP, oxygen concentrations, change in tonicity and mechanical loading may also influence the expression of WNT and BMP antagonists other than GREM1, FRZB and DKK1. Furthermore, such stimulation might also influence the expression of WNT and BMP agonists, at least at the mRNA level. Moreover, it remains to be noted that the current study is indeed limited to mRNA expression and not protein abundance. Nonetheless, clinical studies have shown that $D K K 1$ and $F R Z B$ protein expression in serum and/or synovial fluid are expressed at significantly different levels in patients with osteoarthritis or rheumatoid arthritis compared with control $[53,54]$. Similarly decreased DKK1 levels are found in synovial fluid of animal models of osteoarthritis. Interestingly, $D K K 1$ supplementation has recently been shown to protect from experimental osteoarthritis [55]. Lastly, several other BMP and WNT related proteins have been indicated as being either protective or destructive for articular cartilage [56,57]. These observations are in line with our hypothesis and emphasize that stringent control over DKK1, FRZB and GREM1 expression is required to maintain cartilage homeostasis by preventing hypertrophic chondrocyte differentiation and subsequent catabolism. 


\section{Conclusion}

The current study demonstrates that the mRNA expression of GREM1, FRZB and DKK1 is inversely correlated with the level of cartilage degeneration in osteoarthritis. Moreover, the expression of these regulators of chondrocyte hypertrophy can be influenced by regulators of chondrocyte hypertrophy. Together, this provides a deeper understanding of chondrocyte behavior, cartilage homeostasis and osteoarthritis.

\section{Additional files}

Additional file 1: Figure S1. Showing correlation of GREM1, FRZB and $D K K 1 \mathrm{mRNA}$ expression in preserved and degrading cartilage from the same osteoarthritic joint (OA). (A) GREM1, FRZB and DKK1 mRNA levels were determined in preserved and degenerated cartilage from the same joint. All three antagonists are significantly less expressed in degenerated cartilage compared with preserved cartilage of the same joint $(n=23)$. Broken line indicates the cartilage specimen that belongs to the same donor. (B) GREM1, FRZB and DKK1 were investigated on correlation of mRNA expression. Correlation was determined using Pearson correlation. GADPH, glyceraldehyde 3-phosphate dehydrogenase.

Additional file 2: Figure S2. Showing that cytotoxicity was phenotypically investigated by assessing chondrocyte morphology. Cells were exposed to DMSO, $100 \mathrm{ng} / \mathrm{nl}$ WNT3A, and $100 \mathrm{ng} / \mathrm{ml}$ DKK1 (A), a concentration range of GIN (B) and a concentration range of PKF115-584 (C). A representative picture of each condition over time is shown. To further investigate cytotoxicity, the metabolic activity of chondrocytes exposed to the different conditions was determined using Alamar Blue quantification (D). Data represent the mean of three donors \pm standard deviation. DMSO, dimethylsulfoxide.

Additional file 3: Figure S3. Showing that WNT signaling decreases chordin and chordin-like 2 mRNA expression in primary human chondrocytes. Gene expression was measured by quantitative PCR. Chondrocytes were exposed to a single dose of $10 \mathrm{nM} \mathrm{GIN}, 100 \mathrm{ng} / \mathrm{ml}$ WNT3A (A), (B), $1 \mu \mathrm{M}$ PKF115-584 or $100 \mathrm{ng} / \mathrm{ml}$ DKK1 (C), (D) for up to 72 hours and analyzed for the gene transcription of CHRD (A, C) and CHRDL2 $(B, D)$. Data represent the mean of three donors \pm standard deviation. ${ }^{*} P$ $<0.05$ compared with untreated time point-matched controls. GADPH glyceraldehyde 3-phosphate dehydrogenase.

Additional file 4: Figure S4. Showing effects of activation of canonical WNT signaling on the mRNA expression of GREM1, FRZB and DKK1 in cells other than human chondrocytes. A single dose of $100 \mathrm{ng} / \mathrm{ml}$ WNT3A or $10 \mathrm{nM}$ GIN was added to the culture media of bovine chondrocytes, the MG63 cell line, the SAOS-2 cell line and human bone marrow-derived MSCs. After 48 hours the gene transcription levels of GREM1 (A), FRZB (B) and DKK1 (C) were analyzed. Data represent the mean of three independent experiments (bovine chondrocytes, MG63 and SAOS-2) or two donors (MSCS) \pm standard deviation. ${ }^{*} P<0.05$ compared with untreated time point-matched controls. GADPH, glyceraldehyde 3-phosphate dehydrogenase.

Additional file 5: Figure S5. Showing effect of canonical WNT signaling on the mRNA expression of GREM1, FRZB and DKK1. Primary human chondrocytes were exposed to $100 \mathrm{ng} / \mathrm{ml}$ WNT3A or three different concentrations of PKF115-584 (115). After 48 hours AXIN2 mRNA expression was analyzed by quantitative PCR. (A) Primary human chondrocytes were then exposed to 1 MM PKF115-584 or $100 \mathrm{ng} / \mathrm{ml}$ DKK1 for up to 96 hours. At indicated time points, gene expression was analyzed by quantitative PCR of AXIN2 (B), FRZB (C), DKK1 (D), GREM1, (E) and IDI (F). Data expressed as fold-change relative to control and represents the mean of three donors \pm standard deviation. ${ }^{*} P<0.05$ compared with untreated time point-matched controls $(G)$ or 0 hours of stimulation (A to F). GADPH, glyceraldehyde 3-phosphate dehydrogenase

Additional file 6: Figure S6. Showing effects of $\mathrm{HH}$-mediated or PTHrP-mediated signaling on the mRNA expression of GREM1, FRZB and
DKK1. Chondrocytes were exposed to $2.5 \mu \mathrm{g} / \mathrm{ml} \| \mathrm{HH}, 10 \mu \mathrm{M}$ cyclopamine, or $5 \times 10^{-7} \mathrm{M}$ PTHrP for up to 96 hours. At the indicated time points, mRNA expression was analyzed by quantitative PCR of GREM1 (A), FRZB (B), DKK1 (C), GLI1 (D-E) and CCND1 (F). Data expressed as fold-change relative to control and represent the mean of three donors \pm standard deviation. ${ }^{*} P<0.05$ compared with untreated time point-matched controls. GADPH, glyceraldehyde 3-phosphate dehydrogenase.

\section{Abbreviations}

AXIN2: Axin-related protein; BMP: Bone morphogenetic protein; CHRD: Chordin; CHRDL2: Chordin-like 2; DKK1: Dickkopf 1 homolog (Xenopus laevis); FRZB: Frizzled-related protein; GREM1: Gremlin 1; IHH: Indian hedgehog; IL: Interleukin; MSC: Mesenchymal stromal cell; PBS: Phosphate-buffered saline; PTHrP: Parathyroid hormone-related peptide; RT: Reverse transcriptase; PCR: Polymerase chain reaction; SNP: Single nucleotide polymorphism; WNT: Wingless-type MMTV integration site.

\section{Competing interests}

The authors declare that they have no competing interests.

\section{Authors' contributions}

$\mathrm{JCHL}$ conceived the study. SDB and IM collected and analyzed the gene expression of adult patients with either osteoarthritis or rheumatoid arthritis. $E B M L, N G$ and $H J$ performed and analyzed the IL-1 $\beta$, oxygen tension and tonicity experiments. JCHL performed and analyzed the remaining gene expression experiments. JNP, CAvB and MK participated in the study's design, coordination and data analysis. JCHL and MK drafted the manuscript. SDB, EBML, NG, HJ, IM, JNP and CAvB aided in revising the manuscript's intellectual content. All authors read and approved the final manuscript.

\section{Acknowledgements}

The authors gratefully acknowledge the support of the TeRM Smart Mix Program of the Netherlands Ministry of Economic Affairs and the Netherlands Ministry of Education, Culture and Science. This research was supported by the Project P2.02 OAcontrol of the research program of the BioMedical Materials institute, co-funded by the Dutch Ministry of Economic Affairs, Agriculture and Innovation. The research leading to these results has received funding from the European Union's Seventh Framework Programme (FP7/2007-2011) under grant agreement number 259679. The funders had no role in study design, data collection and analysis, decision to publish, or preparation of the manuscript. The authors acknowledge Michelle Kip for her excellent technical assistance.

\section{Author details}

${ }^{1}$ Department of Developmental BioEngineering, MIRA Institute for Biomedical Technology and Technical Medicine, University of Twente, P.O. Box 217, 7500AE Enschede, the Netherlands. 'Department of Molecular Epidemiology, Leiden University Medical Centre, Section of Molecular Epidemiology, Wassenaarseweg 72, 2333 AL Leiden, Netherlands. ${ }^{3}$ Department of Orthopaedic Surgery, University Hospital RWTH Aachen, Pauwelsstraße 30, 52074 Aachen, Germany. ${ }^{4}$ Department of Tissue Regeneration, University of Twente, Drienerlolaan 5, 7522NB Overijsse, Netherlands.

Received: 1 February 2013 Accepted: 23 August 2013 Published: 19 September 2013

\section{References}

1. Dreier R: Hypertrophic differentiation of chondrocytes in osteoarthritis: the developmental aspect of degenerative joint disorders. Arthritis Res Ther 2010, 12:216.

2. Rountree RB, Schoor M, Chen H, Marks ME, Harley V, Mishina Y, Kingsley DM: BMP receptor signaling is required for postnatal maintenance of articular cartilage. PLOS Biol 2004, 2:e355.

3. van der Kraan PM, Blaney Davidson EN, van den Berg WB: Bone morphogenetic proteins and articular cartilage: to serve and protect or a wolf in sheep clothing's? Osteoarthr Cartilage 2010, 18:735-741.

4. Kawaguchi $\mathrm{H}$ : Regulation of osteoarthritis development by Wnt-beta-catenin signaling through the endochondral ossification process. J Bone Miner Res 2009, 24:8-11. 
5. Thomas RS, Clarke AR, Duance VC, Blain EJ: Effects of Wnt3A and mechanical load on cartilage chondrocyte homeostasis. Arthritis Res Ther 2011, 13:R203

6. Lin AC, Seeto BL, Bartoszko JM, Khoury MA, Whetstone $H$, Ho L, Hsu C, Ali SA, Alman BA: Modulating hedgehog signaling can attenuate the severity of osteoarthritis. Nat Med 2009, 15:1421-1425.

7. Martel-Pelletier J, Alaaeddine N, Pelletier JP: Cytokines and their role in the pathophysiology of osteoarthritis. Front Biosci 1999, 4:D694-D703.

8. Ma B, van Blitterswijk CA, Karperien M: A Wnt/beta-catenin negative feedback loop inhibits interleukin-1-induced matrix metalloproteinase expression in human articular chondrocytes. Arthritis Rheum 2012, 64:2589-2600.

9. Gomez-Barrena E, Sanchez-Pernaute O, Largo R, Calvo E, Esbrit P, Herrero-Beaumont G: Sequential changes of parathyroid hormone related protein (PTHrP) in articular cartilage during progression of inflammatory and degenerative arthritis. Ann Rheum Dis 2004, 63:917-922.

10. Saito T, Fukai A, Mabuchi A, Ikeda T, Yano F, Ohba S, Nishida N, Akune T, Yoshimura N, Nakagawa T, Nakamura K, Tokunaga K, Chung UI, Kawaguchi H: Transcriptional regulation of endochondral ossification by HIF-2alpha during skeletal growth and osteoarthritis development. Nat Med 2010, 16:678-686.

11. Kamekura S, Kawasaki Y, Hoshi K, Shimoaka T, Chikuda H, Maruyama Z, Komori T, Sato S, Takeda S, Karsenty G, Nakamura K, Chung UI, Kawaguchi $\mathrm{H}$ : Contribution of runt-related transcription factor 2 to the pathogenesis of osteoarthritis in mice after induction of knee joint instability. Arthritis Rheum 2006, 54:2462-2470

12. Nilsson O, Parker EA, Hegde A, Chau M, Barnes KM, Baron J: Gradients in bone morphogenetic protein-related gene expression across the growth plate. J Endocrinol 2007, 193:75-84

13. Wang L, Shao YY, Ballock RT: Thyroid hormone interacts with the Wnt/beta-catenin signaling pathway in the terminal differentiation of growth plate chondrocytes. J Bone Miner Res 2007, 22:1988-1995.

14. Minina E, Wenzel HM, Kreschel C, Karp S, Gaffield W, McMahon AP, Vortkamp A: BMP and Ihh/PTHrP signaling interact to coordinate chondrocyte proliferation and differentiation. Development 2001, 128:4523-4534

15. Stewart AJ, Houston B, Farquharson C: Elevated expression of hypoxia inducible factor-2alpha in terminally differentiating growth plate chondrocytes. J Cell Physiol 2006, 206:435-440.

16. Zheng Q, Zhou G, Morello R, Chen Y, Garcia-Rojas X, Lee B: Type X collagen gene regulation by Runx 2 contributes directly to its hypertrophic chondrocyte-specific expression in vivo. J Cell Biol 2003, 162:833-842.

17. Daheshia M, Yao JQ: The interleukin 1beta pathway in the pathogenesis of osteoarthritis. J Rheumatol 2008, 35:2306-2312.

18. Radin EL, Paul IL, Rose RM: Role of mechanical factors in pathogenesis of primary osteoarthritis. Lancet 1972, 1:519-522

19. van der Windt $A E$, Haak E, Das RH, Kops N, Welting TJ, Caron MM, van Til $\mathrm{NP}$, Verhaar JA, Weinans $\mathrm{H}$, Jahr $\mathrm{H}$ : Physiological tonicity improves human chondrogenic marker expression through nuclear factor of activated T-cells 5 in vitro. Arthritis Res Ther 2010, 12:R100.

20. Blanke M, Carl HD, Klinger P, Swoboda B, Hennig F, Gelse K: Transplanted chondrocytes inhibit endochondral ossification within cartilage repair tissue. Calcif Tissue Int 2009, 85:421-433.

21. Jikko A, Kato $\mathrm{Y}$, Hiranuma $\mathrm{H}$, Fuchihata $\mathrm{H}$ : Inhibition of chondrocyte terminal differentiation and matrix calcification by soluble factors released by articular chondrocytes. Calcif Tissue Int 1999, 65:276-279.

22. Fischer J, Dickhut A, Rickert M, Richter W: Human articular chondrocytes secrete parathyroid hormone-related protein and inhibit hypertrophy of mesenchymal stem cells in coculture during chondrogenesis. Arthritis Rheum 2010, 62:2696-2706.

23. Leijten JC, Emons J, Sticht C, van Gool S, Decker E, Uitterlinden A, Rappold G, Hofman A, Rivadeneira F, Scherjon S, Wit JM, van Meurs J, van Blitterswijk CA, Karperien M: Gremlin 1, frizzled-related protein, and Dkk-1 are key regulators of human articular cartilage homeostasis. Arthritis Rheum 2012, 64:3302-3312.

24. Bos SD, Bovee JV, Duijnisveld BJ, Raine EV, van Dalen WJ, Ramos YF, van der Breggen R, Nelissen RG, Slagboom PE, Loughlin J, Meulenbelt I: Increased type II deiodinase protein in OA-affected cartilage and allelic imbalance of $\mathrm{OA}$ risk polymorphism rs225014 at $\mathrm{DIO} 2$ in human $\mathrm{OA}$ joint tissues. Ann Rheum Dis 2012, 71:1254-1258.

25. Moreira Teixeira LS, Leijten JC, Sobral J, Jin R, van Apeldoorn AA, Feijen J, van Blitterswijk C, Dijkstra PJ, Karperien M: High throughput generated microaggregates of chondrocytes stimulate cartilage formation in vitro and in vivo. Eur Cells Mater 2012, 23:387-399.
26. Moreira Teixeira LS, Leijten JC, Wennink JW, Chatterjea AG, Feijen J, van Blitterswijk CA, Dijkstra PJ, Karperien M: The effect of platelet lysate supplementation of a dextran-based hydrogel on cartilage formation. Biomaterials 2012, 33:3651-3661.

27. Shanfield S, Campbell P, Baumgarten M, Bloebaum R, Sarmiento A: Synovial fluid osmolality in osteoarthritis and rheumatoid arthritis. Clin Orthop Relat Res 1988, 235:289-295.

28. Spitters TW, Leijten JC, Deus FD, Costa IB, van Apeldoorn AA, van Blitterswijk CA, Karperien M: A dual flow bioreactor with controlled mechanical stimulation for cartilage tissue engineering. Tissue Eng C Meth 2013, 19:774-783.

29. Engler TA, Henry JR, Malhotra S, Cunningham B, Furness K, Brozinick J, Burkholder TP, Clay MP, Clayton J, Diefenbacher C, Hawkins E, Iversen PW, Li $Y$, Lindstrom TD, Marquart AL, McLean J, Mendel D, Misener E, Briere D, O'Toole JC, Porter WJ, Queener S, Reel JK, Owens RA, Brier RA, Eessalu TE, Wagner JR, Campbell RM, Vaughn R: Substituted 3-imidazo[1,2-a]pyridin-3-yl4-(1,2,3,4-tetrahydro-[1,4]diazepino-[6,7,1-hi]indol-7-yl)pyrrole-2,5-diones as highly selective and potent inhibitors of glycogen synthase kinase-3. J Med Chem 2004, 47:3934-3937.

30. Lepourcelet M, Chen YN, France DS, Wang H, Crews P, Petersen F, Bruseo C, Wood AW, Shivdasani RA: Small-molecule antagonists of the oncogenic Tcf/beta-catenin protein complex. Cancer Cell 2004, 5:91-102.

31. Developmental BioEngineering. http://www.utwente.nl/tnw/dbe/.

32. Adams SL, Cohen AJ, Lassova L: Integration of signaling pathways regulating chondrocyte differentiation during endochondral bone formation. J Cell Physiol 2007, 213:635-641.

33. Zhang D, Ferguson CM, O'Keefe RJ, Puzas JE, Rosier RN, Reynolds PR: A role for the BMP antagonist chordin in endochondral ossification. J Bone Miner Res 2002, 17:293-300.

34. Nakayama N, Han CY, Cam L, Lee Jl, Pretorius J, Fisher S, Rosenfeld R, Scully S, Nishinakamura R, Duryea D, Van G, Bolon B, Yokota T, Zhang K: A novel chordin-like BMP inhibitor, CHL2, expressed preferentially in chondrocytes of developing cartilage and osteoarthritic joint cartilage. Development 2004, 131:229-240.

35. van de Loo AA, van den Berg WB: Effects of murine recombinant interleukin 1 on synovial joints in mice: measurement of patellar cartilage metabolism and joint inflammation. Ann Rheum Dis 1990 49:238-245

36. Leijten JC, Moreira Teixeira LS, Landman EB, Van Blitterswijk CA, Karperien M: Hypoxia inhibits hypertrophic differentiation and endochondral ossification in explanted tibiae. PLoS One 2012, 7:e49896.

37. Gelse K, Ekici AB, Cipa F, Swoboda B, Carl HD, Olk A, Hennig FF, Klinger P: Molecular differentiation between osteophytic and articular cartilage - clues for a transient and permanent chondrocyte phenotype. Osteoarthr Cartilage 2012, 20:162-171.

38. Gazzerro E, Smerdel-Ramoya A, Zanotti S, Stadmeyer L, Durant D, Economides $\mathrm{AN}$, Canalis E: Conditional deletion of gremlin causes a transient increase in bone formation and bone mass. J Biol Chem 2007, 282:31549-31557.

39. Minear S, Leucht $P$, Miller $S$, Helms JA: rBMP represses Wnt signaling and influences skeletal progenitor cell fate specification during bone repair. J Bone Miner Res 2010, 25:1196-1207.

40. He XC, Zhang J, Tong WG, Tawfik O, Ross J, Scoville DH, Tian Q, Zeng X, He $X$, Wiedemann LM, Mishina Y, Li L: BMP signaling inhibits intestinal stem cell self-renewal through suppression of Wnt-beta-catenin signaling. Nat Genet 2004, 36:1117-1121.

41. Wilson SI, Rydstrom A, Trimborn T, Willert K, Nusse R, Jessell TM, Edlund T: The status of Wnt signalling regulates neural and epidermal fates in the chick embryo. Nature 2001, 411:325-330.

42. Miclea RL, van der Horst G, Robanus-Maandag EC, Lowik CW, Oostdijk W, Wit JM, Karperien M: Apc bridges Wnt/beta-catenin and BMP signaling during osteoblast differentiation of KS483 cells. Exp Cell Res 2011, 317:1411-1421.

43. Tuli R, Tuli S, Nandi S, Huang X, Manner PA, Hozack WJ, Danielson KG, Hall DJ, Tuan RS: Transforming growth factor-beta-mediated chondrogenesis of human mesenchymal progenitor cells involves $\mathrm{N}$-cadherin and mitogen-activated protein kinase and Wnt signaling cross-talk. J Biol Chem 2003, 278:41227-41236.

44. Zhu M, Tang D, Wu Q, Hao S, Chen M, Xie C, Rosier RN, O'Keefe RJ, Zuscik $M$, Chen D: Activation of beta-catenin signaling in articular chondrocytes leads to osteoarthritis-like phenotype in adult beta-catenin conditional activation mice. J Bone Miner Res 2009, 24:12-21. 
45. Zhu M, Chen M, Zuscik M, Wu Q, Wang YJ, Rosier RN, O'Keefe RJ, Chen D: Inhibition of beta-catenin signaling in articular chondrocytes results in articular cartilage destruction. Arthritis Rheum 2008, 58:2053-2064.

46. Kaler P, Augenlicht L, Klampfer L: Macrophage-derived IL-1beta stimulates Wnt signaling and growth of colon cancer cells: a crosstalk interrupted by vitamin D3. Oncogene 2009, 28:3892-3902.

47. Saxon L, Finch C, Bass S: Sports participation, sports injuries and osteoarthritis: implications for prevention. Sports Med 1999, 28:123-135.

48. Haapala J, Arokoski JP, Hyttinen MM, Lammi M, Tammi M, Kovanen V, Helminen HJ, Kiviranta I: Remobilization does not fully restore immobilization induced articular cartilage atrophy. Clin Orthop Relat Res 1999, 362:218-229

49. Madhavan S, Anghelina M, Rath-Deschner B, Wypasek E, John A, Deschner J, Piesco N, Agarwal S: Biomechanical signals exert sustained attenuation of proinflammatory gene induction in articular chondrocytes. Osteoarthritis Cartilage 2006, 14:1023-1032.

50. Sen B, Styner M, Xie Z, Case N, Rubin CT, Rubin J: Mechanical loading regulates NFATC1 and beta-catenin signaling through a GSK3beta control node. J Biol Chem 2009, 284:34607-34617.

51. Pan Z, Wang Z, Yang H, Zhang F, Reinach PS: TRPV1 activation is required for hypertonicity-stimulated inflammatory cytokine release in human corneal epithelial cells. Invest Ophthalmol Vis Sci 2011, 52:485-493.

52. Chan BY, Fuller ES, Russell AK, Smith SM, Smith MM, Jackson MT, Cake MA, Read RA, Bateman JF, Sambrook PN, Little CB: Increased chondrocyte sclerostin may protect against cartilage degradation in osteoarthritis. Osteoarthritis Cartilage 2011, 19:874-885.

53. Corallini F, Secchiero P, Castellino G, Montecucco M, Trotta F, Zauli G: Circulating levels of frizzled-related protein (FRZB) are increased in patients with early rheumatoid arthritis and decrease in response to disease-modifying antirheumatic drugs. Ann Rheum Dis 2010, 69:1733-1734.

54. Honsawek S, Tanavalee A, Yuktanandana P, Ngarmukos S, Saetan N, Tantavisut S: Dickkopf-1 (Dkk-1) in plasma and synovial fluid is inversely correlated with radiographic severity of knee osteoarthritis patients. BMC Musculoskel Dis 2010, 11:257.

55. Oh H, Chun CH, Chun JS: Dkk-1 expression in chondrocytes inhibits experimental osteoarthritic cartilage destruction in mice. Arthritis Rheum 2012, 64:2568-2578

56. Reddi AH: Interplay between bone morphogenetic proteins and cognate binding $s$ in bone and cartilage development: noggin, chordin and DAN. Arthritis Res 2001, 3:1-5.

57. Luyten FP, Tylzanowski P, Lories RJ: Wnt signaling and osteoarthritis. Bone 2009, 44:522-527.

\section{doi:10.1186/ar4306}

Cite this article as: Leijten et al: GREM1, FRZB and DKK1 mRNA levels correlate with osteoarthritis and are regulated by osteoarthritisassociated factors. Arthritis Research \& Therapy 2013 15:R126.

\section{Submit your next manuscript to BioMed Central and take full advantage of:}

- Convenient online submission

- Thorough peer review

- No space constraints or color figure charges

- Immediate publication on acceptance

- Inclusion in PubMed, CAS, Scopus and Google Scholar

- Research which is freely available for redistribution 